\title{
Osteoporotic Patients are Suitable Candidates for Dental Implants or Not??
}

\author{
Preetika Bansal* and Sukhmeet Kaur \\ Department of Periodontics, Dasmesh Institute of Research and Dental Sciences, India
}

*Corresponding author: Preetika Bansal, Professor, Department of Periodontics, Dasmesh Institute of Research and Dental Sciences, Faridkot, Punjab, India

Submission: 觜 July 14, 2018; Published: 漹 July 23, 2018

\begin{abstract}
Dental implants are one of the best ways to replace the missing teeth. The success rate of dental implants depends upon various factors including local and systemic factors. Osteoporosis is skeletal disease characterized by compromised bone density with increased bone fragility and increased risk of fracture. Osseointegration of an implant depends upon host bone quality and quantity, its healing capacity and various other systemic conditions. So, here we discuss whether the osteoporotic patients are suitable candidates for dental implants or not?
\end{abstract}

Keywords: Dental implants; Bone; Osteoporosis; Osseointegration

\section{Introduction}

Dental implants are the best treatment option to replace the missing natural teeth and maintain bone, function, esthetics and phonetics and improving the quality of life. The demand of dental implants is increasing day by day to improve the life expectancy since aging is accompanied by increased tooth-loss. Collaterally, chronic illness like various forms of cancer and other diseases including skeletal and metabolic disorders such as osteoporosis and diabetes are also increasing respectively. Osteoporosis is a bone resorptive multi factorial generalized skeletal disease characterized by decreased bone strength and abasement of the micro architecture of the bone tissue resulting in fragility of the bone tissue with resultant greater risk of fractures [1]. Various factors such as calcium and vitamin D deficiency and genetic factors are involved in the etiology of osteoporosis but the post menopausal estrogen deficiency is the major known etiology, because it regulates bone remodeling and the deficiency of it induces imbalance of a bone remodeling with increase in bone resorption than bone formation, leading to bone fragility and increasing risk of fracture. Numerous treatment options are available to treat the osteoporosis including balanced diet, smoking prevention, weight bearing exercises and systemic pharmacological treatment modalities like Estrogen replacement therapy, bisphosphonates, selective estrogen receptor modulators, calcitonin and parathyroid hormone which aim to increase bone mass [2]. However, long term usage of all these treatment modalities has their own disadvantages. The success rate of the dental implants depends upon several local and systemic factors which affect the healing process. Various systemic conditions such as cardiovascular disease, diabetes mellitus, Sjogren's syndrome, osteoporosis may affect the healing process of implants. Bornstein et al. [3]. The success of dental implants depends upon osseointegration of dental implant. Osseointegration is a healing process which over reckons bone quantity and quality. Bone density has been identified as one of the major factors affecting the primary stability of an implant. Various studies [4-6] concluded that patients with osteoporosis do not have a higher risk of early implant failure compared to non-osteoporotic patients. Merheb et al. [7] in 2016 stated that there is an existence of a moderate relationship between the skeletal bone density and implant stability. Safe protocols should be followed while treating the osteoporotic patients with dental implants and longer healing times could be recommended. Thus, the prerogative that the dental implants might be contraindicated in patients with osteoporosis is based upon the presumption that osteoporosis may affect the human jaws in the same method which it does affect other bones of the body. However, till date, there are no studies which conclude that osteoporosis increase the prevalence of peri-implantitis, chances of failure of dental implants and no data available to contraindicate the dental implants in osteoporotic patients. De Baz et al. [8] conducted study in 2015 to compare the quality of life of osteoporotic women with dental implant retained restorations as well as those who do not and concluded that implant retained oral rehabilitation of missing teeth has a statistically significant impact over non-implant or fixed restorations. Osteoporosis has no detrimental effect on implant failure rates neither on percentage of osseointegration. Here at the end, osteoporotic patients can be successfully treated with the 
dental implants with more precautions, proper treatment planning, and longer healing period. Furthermore longitudinal studies are required to be done to know the long term success rate of dental implants in osteoporotic patients.

\section{References}

1. (1993) Consensus development conference: diagnosis, prophylaxis, and treatment of osteoporosis. Am J Med 94 (6): 646-50.

2. Brown JP, Frame H, Fortier M, Lalonde A, Papaioannou A, et al. (2006) Canadian consensus conference on osteoporosis, 2006 update. J Obstet Gynaecol Can 28(Suppl 2): 95-112.

3. Bornstein MM, Cionca N, Mombelli A (2009) Systemic conditions and treatments as risks for implant therapy. Int J Oral Maxillofac Implants 24: 12-27.

4. Amorim MA, Takayama L, Jorgetti V, Pereira RM (2007) Comparative study of axial and femoral bone mineral density and parameters of mandibular bone quality in patients receiving dental implants. Osteoporos Int 18(5): 703-709.

5. Holahan CM, Koka S, Kennel KA, Weaver AL, Assad DA, et al. (2008) Effect of osteoporotic status on the survival of titanium dental implants. Int J Oral Maxillofac Implants 23(5): 905-910.

6. Temmerman A, Rasmusson L, Kubler A, Thor A, Quirynen M (2017) An open, prospective, non-randomized, controlled, multicentre study to evaluate the clinical outcome of implant treatment in women over 60 years of age with osteoporosis/osteopenia: 1-year results. Clin Oral Implants Res 28(1): 95-102.

7. Mehrab J, Temmerman A, Rasmusson L, Kubler A, Thor A, et al. (2016) Influence of skeletal and local bone density on dental implant stability in patients with osteoporosis. Clin Implant Dent Relat Res 18(2): 253-260.

8. De Baz C, Hahn J, Lang L, Palomo L (2015) Dental implant supported restorations improve quality of life in osteoporotic women. Int J Dent 2015: 451923.
Creative Commons Attribution 4.0

International License

For possible submissions Click Here
Submit Article

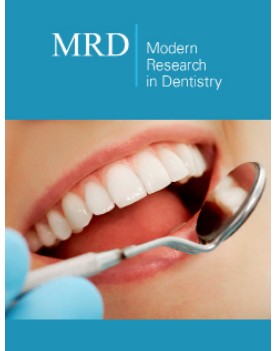

\section{Modern Research in Dentistry}

\section{Benefits of Publishing with us}

- High-level peer review and editorial services

- Freely accessible online immediately upon publication

- Authors retain the copyright to their work

- Licensing it under a Creative Commons license

- Visibility through different online platforms 